$\left.\begin{array}{l}\text { Sournals } \\ \text { INTERNATIONAL JOURNAL OF } \\ \text { ORGANIZATIONAL LEADERSHIP }\end{array}\right) \begin{gathered}\text { INDUSTRIAL } \\ \text { MANAGEMENT } \\ \text { INSTITUTE }\end{gathered}$

\title{
Assessing the role of architectural space in enhancing human force productivity
}

\author{
Zeynab Yousefizadeh*, Seyed Hadi Ghoddusifar
}

Department of Art and Architecture, South Tehran Branch, Islamic Azad University, Tehran, Iran

\begin{abstract}
Keywords:

Architectural Space, Productivity, Human Resources

Received

12 April 2016

Received in revised form 28 May 2016

Accepted

05 June 2016

Correspondence:

z.yousefi@iauba.ac.ir

In recent years, specializing different trends has faded role of architectural space and architectural design in management and leadership of organizations. For example, today, fewer management specialists think about architectural design issues and fewer architects think deeply of leadership, management, and systematic thought. While it seems that what these two areas have in common is significantly beneficial. In any organization, human resources are main factor, thus, recognition of human and promoting criteria of human resource productivity is essential to achieve success of the organization. Today, working environment in organizations is of important issues addressed continuously in meetings and papers and importance and quality of creating an effective and appropriate environment for human resources is emphasized; in fact, workplace has a direct relation to increase or decrease the organizational performance. There are factors that if they go unnoticed in design of workplace, organizational works will not be done properly and they will face a decrease in returns. This study aims to recognize the relation between the architectural space and promoting the human resource productivity that accordingly, it is required to identify the methods of promoting human resource productivity in organizations and discern the impact of environment on behavior.
\end{abstract}

(C)AIMI Journals

\section{Introduction}

The most important power source of organizations is unique human resources in various specialized fields and this critical issue must be addressed deeply and approaches, processes, and various and enriched functions of human resources should be reviewed. As organizations' structure and performance get more complex, some concerns of managers and leaders of organizations are to organize a workplace and to create a calm and productive atmosphere in organizations which leads to more activation of human resources, their vitality, eliminating 
probable risks, increase in quality of work, reducing depression, growth in production, growth of positive services, and ultimately, achieving desired efficiency. Results of studies in human resources show that development of productive human resources directly plays a key role in achieving organizational goals (Bagheri \& Azemati, 2015).Creating happiness and satisfaction is so important for human resources to try to do their best in duties by a happy spirit and sense of security in job (Dessler, 2015). Accordingly, this study attempts to answer the question that how can organizing the space and working environment lead to productivity improvement and staff empowerment?

\section{Social Capital and its Productivity Concept of Social Capital}

Concept of social capital includes notions such as trust, cooperation, and solidarity among members of a group or a community which constitute a purposeful system guiding them towards achieving worthwhile goals (Ackoff, 1999). In traditional views of development management, economic and physical capitals and human resources played the most significant role; but now to develop, management needs social capital more than those capitals because utilizing other capitals will not be optimal without this capital. What is understood from numerous definitions of social capital is that the concept is sum of those connections and social networks within community and also level of trust and cooperation between existing relationships (Khodayarian, Vanaki, Navipour, \& Vaezi, 2011).

\section{Generalizing Social Capital to the Organization}

Organizational social capital is defined as a source of social relations within the organization that is specified through collective goal and confidence shared by all levels of members. Reason of organizations' attention to social capital in recent years is importance of knowledgebased organizations and networked economic growth. Social capital may have advantages and disadvantages for the organization due to its nature, and development of social capital requires understanding of its costs and relative benefits that is essential for managers interested in investing in this area (Faqihi \& Feizi, 2006).

\section{Human Resource Productivity}

Human resources are the most significant capital of an organization. Improving labor productivity will also improve productivity of other factors. Respecting human resources and investment in this area can transform any organization and make it successful in achieving its objectives (Tavassoli, 2014).

Since productivity is an organizational gem that is able to guarantee stability and survival of organizations and be a mechanism for gaining competitive advantage, what leads to labor productivity within an organization is that the personnel become compatible with activities and jobs in terms of personality, interests, and emotions. Consequently, by interest in work, motivation, responsibility, and thereby directly or indirectly, organizational productivity will improve (Baqi Nasrabadi \& Shadaloie, 2010).

Productivity is scientifically maximizing use of resources, labor, and measures to reduce costs and satisfy personnel, managers, and customers. Other definitions of productivity refer to 
the most perfect use of human resources to move toward the organization's goals in shortest time and at low cost. Today, role and importance of human resources has been identified as the most considerable factor in production process and providing services in human societies. Given the stages of human civilization, it is found that role of human resources has evolved from simple labor to human capital because technological progress is inefficient without development of human resources. At the present time, injection of financial resources is not main factor of development any more, but also progress of human resource evolution and productivity causes promotion of organizations and consequently, development of economic systems around the world; so that human capitals determine amount of material assets. So High productivity growth, especially human resource productivity affects all economic and social activities (Gholipour, 2013).

Proper use of human resources as the most valuable and greatest wealth of any society is noticed significantly by government. In the other words, it can be said that human is both target and cause of development and achieving aims of development considerably relies on quality of handling and management of this vital source. Therefore, resource productivity is one of the important foundations of any organization or institute (Faqihi \& Feizi, 2006).

There are different attitudes to specifying effective factors of productivity; however, promoting the level of productivity cannot only be result of one certain factor, but also it should be resulted from combination of various items including ability or preparation for work, job recognition, organizational support, motivation or desire, performance feedback, credit, and environmental compatibility. External factors that can affect a person's performance constitute the environment. These factors will impact on performance of individuals. However, if workplace is not suitable, human resource productivity will decline in spite of personnel with ability, recognition, support, and other necessary conditions (Taheri, 2003).

\section{Role of Architectural Space in Organizational Behavior of Personnel Organizational Behavior}

In general, study on people at work is called organizational behavior study. Organizational behavior is a discipline that investigates impact of individuals, groups, and structure on behavior within organizations and its goal is to apply this knowledge to improve effectiveness of the organization. Since organizational behavior particularly relates to employment and working conditions, it is focused on behavior associated with issues such as job, work, absenteeism, staff turnover, productivity, employee performance, and management (Robbins, 2013).

\section{Change in Nature of Workplace}

Recent research on job planning provides evidence that method of organizing elements in a job could be a factor to strengthen or weaken person's efforts.

\section{Architectural Design}

A good plan is based on both feeling and wisdom. To make findings of sciences like management and practical environmental psychology, change in nature of design from a "mere artistic work" to a "scientific" profession or art must be accepted. 
In the past, architects were just architects and scientists focused on some sciences and information about those apparently essential branches; but modern science ignores no area and all live based on that. Therefore, architects also design and build new buildings according to new scientific data. Architecture is not a free artistic activity but a science-based profession considered to solve a problem. Design aims to create environments and their main parts which are appropriate for users. Designing buildings and other physical environments must comply with human personalities and characteristics and be suitable and useful for them. Design should be based on knowledge of quality of interaction between people and the environment. In this case, design becomes a practice of science based on research and it should be based on the best knowledge available at any time.

On the one hand, in today's world, results of research increases in various scientific fields every day and most of the research aims to enhance the quality of human living and improve its life. On the other hand, design as an interdisciplinary and multidisciplinary notion must be able to apply these findings mostly obtained in basic science or in the other words, it should literally give mankind these findings via designing environment of living (Shahcheraqi \& Bandarabad, 2015). There are three strategies to fulfill scientific design aimed to apply environmental psychology findings, namely collective design, reviewing design process, and link between research and design. These strategies are to achieve scientific design as a whole and its goal is to get rid of current crises of human living environment.

\section{Collective Design}

Since the design of human living environment is an interdisciplinary and multidisciplinary area, various technical, experimental, natural, and social sciences experts should work together in each design. That is why design of environment should progress within a group and through interchange of ideas among experts of various disciplines. In fact, collective design is the only solution to utilize research results in contemporary life conditions.

\section{Reviewing Design Process}

To apply findings of environmental psychology in two realms of cognitive sciences and behavioral sciences, common design processes should be reconsidered. In other words, process-oriented design is useful, not goal-oriented design. In the process of functionalist design, people's behaviors provide initial information diagrams for designers. Designers notice this information in environmental design process and thus, propose projects regarding free behavior of individual within the environment. Therefore, a conversation emerges between people's behavior and designer's opinion.

\section{Link between Research and Design}

Scientific design needs continuous research and use of its findings. Sometimes in similar circumstances, research results of other groups can be used in design; but sometimes, a specific study must be done to design a project in regard with cultural conditions in a certain country. Hence, research and design should move in parallel way. Basically, environmental psychologists collect research data through observing physical signs in the environment or observing individual behavior within the environment. 
Observing physical signs in the environment and focusing on them is common among architects and urban planners. Because they study the environment, they collect required data and decide for future conditions of the environment through observation.

Totally, it should be noted that if we believe in design as an artistic science in recent years, we must accept that respect for three approaches of strengthening collective design, reviewing design process, and link between research and design can guide us toward a brilliant direction. Since considering these three approaches can help designers practically apply findings of environmental psychology, it seems that employing findings of other sciences may be effective and beneficial to architectural planning and design, landscape, and urbanization.

Designers and planners can employ excessively growing research results of environmental psychology in their works and significantly help to promote mental and behavioral health affected by physical environment in human societies (Shahcheraqi \& Bandarabad, 2015).

\section{Explanation of Promoting Criteria of Human Resource Productivity via Architectural Design}

A lot of time in every human's life is spent in man-made spaces impacting on the human psyche as well as forming it. The environment contains the human psyche and the human mind involves the environment. To this end, architecture has a key role in this formation (Pakzad \& Bozorg, 2014). Certainly, all architects and designers do not have a philosophical view about design, but all should be aware of its impact on human while designing and creating an environment and they ought to design consciously. Now, given extensive research in the realm of environmental psychology, scientific findings make designers and architects aware; so that they should review design process if they have made some decisions based on their personal experience or preferences in design stages. Findings of behavioral science and cognitive science warn designers against experimentation or personal taste in many cases (Shahcheraqi \& Bandarabad, 2015).

If working environment is well designed, it leads to employee satisfaction, sense of ownership and belonging, qualitative and quantitative increase in work, cooperation, staff participation and association and ultimately, job satisfaction. Comfort may be functional, but job satisfaction needs intelligent design. One of the most important factors in environmental psychology of workplace is to check out the spaces according to satisfaction, comfortable performance (comfort), and production (achievement); so, if a person is satisfied in the workplace, his performance is good and his career achievement is positive, as a result.

\section{Formal Offices}

Personnel of offices spend a lot of time in these spaces. So today, these spaces have been concerned like residential spaces and designers and architects have become interested in making office spaces pleasant; attention to relationship between inside and outside, using natural elements, continuity of design and color, spatial diversity and intelligent use of furniture that can be seen in many successful projects today, improve quality of offices to achieve specified objectives.

Work environment has a direct relation to increase or decrease organizational performance. There are factors that if paid no attention, organizational work would not be done properly and returns would decline. Moreover, high noise causes reduced efficiency of employees in 
offices.

The results demonstrate that high temperature affects people's cognitive, physical, and perceptual performance. Factors such as type of work determines amount of activity done by a person in a certain time and also periods of leave. Formal offices are generally divided into two categories, namely conventional offices with separate rooms and open offices. Research has shown that due to lack of physical territory in offices with open plan (open offices), employees make a new immutable territory to feel more comfortable; for example, they sit behind one desk every day, they use one monitor or they hang their coats in one place every day. Although open offices encourage staff to more participation and teamwork, these offices are stressful because people can conveniently access to information of each other, there is a lot of noise, and they stimulate a defensive manner in people. Personnel have personal control over their work space in conventional offices that it results in positive points such as less distraction, better performance, less stress, decision-making on an individual basis and ultimately, more satisfaction with work environment. However, one of its negative points is lack of participation with others. Researchers believe that ability to see without being seen is a natural need that satisfies personnel in an office. Moreover, some research has studied personnel's manner of sitting in offices and found that people tend to sit across each other when competing; but they tend to sit next to each other when cooperating with each other. They also tend to sit around the corner when talking to each other.

\section{Innovative Offices}

Today, offices of creative professions have changed. These offices are not as common offices which possess spaces to relax and have fun. This revolution began by Google Inc. that provided offices in which comfortable seating areas and entertainment and play facilities were created for its employees. Many companies and universities attempt to design environments to promote working level and personnel's creativity.

Creativity is often known and described by four factors such as person, process, product, and place. Following this, the environment (place) has a fundamental role in procedure of creativity among them and research has verified the effect of the environment on creativity. In the past, research was mostly related to the effects of workspace on production but recently, research has been led to creativity. These studies have different methods to support creativity including supporting creative interaction, supporting creative opinion and insight, supporting individual features, and supporting creative environments.

Physical environment where producers are physically there should support process of creativity. In other words, physical environment should affect process of creativity. So far, many researchers have tried to find features of environments which lead to creativity. According to the results of the research to date, points such as complexity of visual details, easy visual access to information and simultaneous stimulation of the senses, possibility of different options for seating, even sitting on the ground (soft carpet) as well as variety of colors in offices impact on staff's creativity and several examples relating to the elements of a real innovative space are mentioned in Table 1 (Shahcheraqi \& Bandarabad, 2015). 
Table 1

Elements of a Real Innovative Space (Shahcheraqi \& Bandarabad, 2015)

\begin{tabular}{ll}
\hline Elements & Example \\
\hline Flowers and Plants & Flowers and Plants within Interior Space \\
TV and Piano & Creative Parts \\
Window & $\begin{array}{l}\text { Looking at Nature, Visual Access to Trees, Plants, Rivers and other Natural } \\
\text { Elements }\end{array}$ \\
Furniture & Type of Table and Chair Inside the Space \\
Amount of Light & Natural and artificial \\
View & Visual Access to Outside \\
Positive Sound & Good Sound of Music or Sounds of Nature \\
Safety & Providing Privacy far from Others' Presence or Gaze \\
Soothing Colors & Colors Providing Calm and Comfort such as Green, Blue, Violet Blue \\
Inspiring Colors & Motivating Colors \\
Artistic Works & Using Innovative Art Inside the Building \\
Playing Facilities & Like Chess \\
Fireplace & To Warm the Room \\
Aquarium, Spiral Stairs & To Stimulate the Senses such as Vision \\
Projector & Multimedia Communication \\
\hline
\end{tabular}

\section{Industrial Workplace}

Similar to other work environments, industrial workplace affects both feeling and psychological aspects of staff. These two types of environmental impact are sometimes separated and sometimes integrated and one causes the other. In numerous studies, it has proven that physical factors of the environment affect staff. These factors include air temperature in the workplace, air flow, humidity, ventilation and sufficient fresh air supply, and environmental safety. Some researchers suggest several items for personnel's rest in industrial environments that indicate appropriate guidelines for designing these spaces. Industrial psychology is defined as the study on human behavior within aspects of life that are relevant to work and employing knowledge of human behavior to reduce its difficulties on the job.

Industrial and organizational psychology is defined as application of psychological principles at work and study on factors affecting employees in organizations. Industrial and organizational psychology means finding scientific principles and applying them in the workplace. Today, phenomena like individual differences, organizational structure, compensation and salary, collective structure of organization, system of punishment and encouragement, designing tools for working, working conditions, and personnel's motivation and are concerned in application of workplace psychology and it is foreseeable that in the future, workplace psychology or industrial and organizational psychology will concern interaction between staff and other factors such as organization, working conditions, productivity, artificial humans (robots) rather than individual factors.

Industrial psychology and considering physical form of industrial environments is so important for employers in different industries and they are addressed in various cases. 
However, neglecting this matter in our country is one of the factors in low quality of work in industrial environments; so, it is obvious that people who work in these environments spend their nights in small and poor containers near their harsh working environments without their human needs being noticed (Shahcheraqi \& Bandarabad, 2015).

\section{Discussion and Conclusion}

This study tried to adopt an interdisciplinary look for deeper analysis of relationship between human resource management and architectural design of environment. Therefore, based on an analytical and critical research methodology, this paper investigates and analyzes literature of environmental psychology, architecture and human resource management and it attempts to recognize interfaces of these areas by logical reasoning. In this regard, two general criteria of social capital and its productivity and role of architecture in organizational behavior of human resources are analyzed and result of this approach explains promoting criteria for human resource productivity via architectural design. This paper attempted to introduce and analyze the impact of environmental psychology within workplaces in architectural scale. Today, since no wise architect ignores aspects of compatibility with environmental climate and reducing energy consumption in his projects, designers are expected to be aware of influences of the environment on human psychological dimensions in the future and psychological layers of architectural designs to be more precise and evident in architectural documents while working on projects.

Main challenge of human resources in organizations is how they can help their personnel to improve and empower their performance. Human resource management is based on organizational behavior concepts that achieve organizational targets through systematic efforts to identify, understand, and control human behavior. Human resource management seeks to guarantee human resources productivity and profitability of organization as well as providing some part of human needs. Recruitment and placement processes, improvement, motivation and retention of human resources, and ensuring their efficiency and effectiveness largely depend on amount of care applied in choosing the best way to improve employees' performance. Architects and environmental designers are required to cooperate indecisionmaking process of executives and leaders of organizations about form of workplaces and promote human resources productivity and ultimately, achieve strategic purposes of the organization by intervening in organization's environment and providing optimal conditions for presence, activity, and social interaction of individuals within the organization.

\section{References}

Ackoff, R. L. (1999). Re-creating: A design of organizations for the $21^{\text {st }}$ century. USA: Oxford University Press.

Bagheri, M., \& Azemati, H. (2015). Enhancement of citizens' physical-mental health by environmental design and urban landscape. Human \& Environment Quarterly, 26(15), 83-88.

Baqi Nasrabadi, A., \& Shadaloie, N. (2010). The role of human resources in organizational productivity. Hosun Magazine, 26, 35-43.

Dessler, G. (2015). Human resource management (14 ${ }^{\text {th }}$ ed.). Upper Saddle River: Prentice Hall.

Faqihi, H., \& Feizi, T. (2006). Social capital: A new approach in organization. Knowledge Management Quarterly , 19(72), 23-46.

Gholipour, A. (2013). Human resource management: Concepts, theories, and applications (5 ${ }^{\text {th }}$ ed.). Tehran: SAMT. 
Khodayarian, M., Vanaki, Z., Navipour, H., \& Vaezi, A. (2011). The impact of nursing management development programs on clinical competence of nurses of cardiac care. Behbood Magazine, 15(1), 40-50

Pakzad, J., \& Bozorg, H. (2014). Alphabet of psychological environment for designers (2 ${ }^{\text {nd }}$ ed.). Tehran: Armanshahr Press.

Robbins, S. P., \& Judge, T. A. (2009). Organizational behavior. Upper Saddle River, New Jersey: Prentice Hall Inc.

Shahcheraqi, A., \& Bandarabad, A. (2015). Surrounded in environment: Application of environmental psychology in architecture and urbanism ( $1^{\text {st }}$ ed.). Tehran: Publication of Jahad-e Daneshgahi.

Taheri, S. (2003). Productivity analysis in organizations. Tehran: Amir Kabir Publications.

Tavassoli, M. (2014). Quality management and efficiency. Tehran: Afrang Press. 